\title{
Help-Seeking for Child Psychopathology: Pathways to Informal and Professional Services in The Netherlands
}

\author{
MARIEKE ZWAANSWIJK, Ph.D., JAN VAN DER ENDE, M.S., PETER F. M. VERHAAK, Ph.D., \\ JOZIEN M. BENSING, PH.D., AND FRANK C. VERHULST, M.D.
}

\begin{abstract}
Objective: To devise and test a model describing the process of help-seeking for child psychopathology in professional and informal service settings. Method: Using structural equation modeling, associations between several help-seeking stages, and the influence of child, family, and context characteristics on these stages were investigated in 246 Dutch children (4-11 years old) between April 2000 and July 2002. Children were selected for having emotional or behavioral problems from a representative general practice sample; $68 \%$ of the selected children participated. Results: School personnel played an important role in the process of help-seeking for child psychopathology, in both detecting service need and the provision of and the referral for help. Although Dutch general practitioners are supposed to be gatekeepers of mental health care, their role in help-seeking for child psychopathology was limited. Various family characteristics were shown to influence service need and informal or professional help-seeking. The influence of child characteristics on the help-seeking process was limited. Conclusions: Educating parents about child psychopathology and the availability and accessibility of care, improving general practitioners' skills in detecting child psychopathology, and direct contact of mental health professionals with general practitioners and schools may enhance access to care for children in need. J. Am. Acad. Child Adolesc. Psychiatry, 2005;44(12):1292-1300. Key Words: mental health services, child, psychopathology, health behavior, social support.
\end{abstract}

The pathway that leads to professional mental health care for children with psychopathology is paved with obstacles, causing a discrepancy between the number of disordered children in the community and those receiving professional care (Burns et al., 1995; Flisher et al., 1997; Leaf et al., 1996; Pavuluri et al., 1996; Verhulst and Van der Ende, 1997). Understanding which

Accepted June 28, 2005.

Dr. Zwaanswijk is with the Netherlands Institute for Health Services Research (NIVEL), Utrecht, the Netherlands and the Department of Child and Adolescent Psychiatry, Erasmus University Medical Center, Rotterdam; Dr. Verhaak is with NIVEL, and Dr. Bensing is with NIVEL and Utrecht University, the Netherlands; Dr. Verhulst and J. van der Ende are with the Department of Child and Adolescent Psychiatry, Erasmus University MC, Rotterdam, the Netherlands.

Supported by grant 2100.0064 from the Netherlands Organization for Health Research and Development.

Article Plus (online only) materials for this article appear on the Journal's Web site: www.jaacap.com.

Reprint requests to Dr. Marieke Zwaanswijk, NIVEL, P.O. Box 1568, 3500 BN Utrecht, The Netherlands; e-mail: M.Zwaanswijk@nivel.nl.

0890-8567/05/4412-1292@2005 by the American Academy of Child and Adolescent Psychiatry.

DOI: 10.1097/01.chi.0000181038.98712.c6 factors are involved in the help-seeking process may provide suggestions on how to increase service use for these children. A fruitful way to integrate findings on helpseeking stages and their determinants is to include them in one comprehensive model. Although many models concerning the help-seeking process have been formulated (e.g., Andersen, 1995; Fischer et al., 1983; Goldberg and Huxley, 1980, 1992), few specifically apply to help-seeking for child and adolescent psychopathology.

A first example is the model by Verhulst and Koot (1992), who have adapted the Goldberg and Huxley (1980, 1992) model to make it applicable for child and adolescent help-seeking. In this model, help-seeking is described as consisting of five subsequent levels, each separated by a filter. The filters refer to (1) parental problem recognition and consultation of a general practitioner (GP), (2) problem recognition by the GP, (3) referral to psychiatric care, and (4) referral to inpatient psychiatric care. Because general practice is the formal point of entry into mental health care in the United Kingdom and the Netherlands, and GPs are supposed 
to function as gatekeepers, a central role is attributed to the GP.

Logan and King (2001) have expanded this model by including parents' initial awareness of child problems as a stage preceding parental problem recognition. Their definition of problem recognition explicitly involves an evaluative element in which parents acknowledge that the child's problems are severe enough to require help-seeking. In this respect, it resembles Andersen's (1995) construct of perceived need for help.

The focus on the parental side of the help-seeking process is broadened by Costello et al. (1998), who stressed the importance of family, school, and context in their comprehensive model of access to child mental health services.

To our knowledge, researchers have thus far only investigated particular help-seeking stages in isolation from each other, without testing a help-seeking model as a whole. Our aim is to combine several existing helpseeking models and findings on determinants of helpseeking into one comprehensive model (Fig. 1). Testing this model will not only provide insight into the influence of several determinants on stages of the help-seeking process but will also clarify the way in which the helpseeking stages influence one another.

Our focus is on the parent-mediated pathway to child mental health care. This does not imply a disregard for the roles that other adults can play in the help-seeking process. By including several family- and context-based determinants, we acknowledge the ecological nature of the process. Our model does not include adolescent helpseeking because this is characterized by more autonomy and is influenced by different factors than help-seeking for child psychopathology (Zwaanswijk et al., 2003).

Following Logan and King (2001), the first step in the help-seeking process is assumed to be parents' initial awareness that their child shows problematic behaviors or emotions (parent report of child problems [Fig. 1]), followed by parents' need for services. Service need is defined as the presence of parent-reported child psychopathology and associated functional impairment (Brewin et al., 1987). This operationalization is somewhat more objective than previously used measures of service need, in which parents were directly asked whether their child was in need of help (e.g., Verhulst and Van der Ende, 1997).

Based on previous research and theory (Logan and King, 2001; Verhulst and Van der Ende, 1997), the

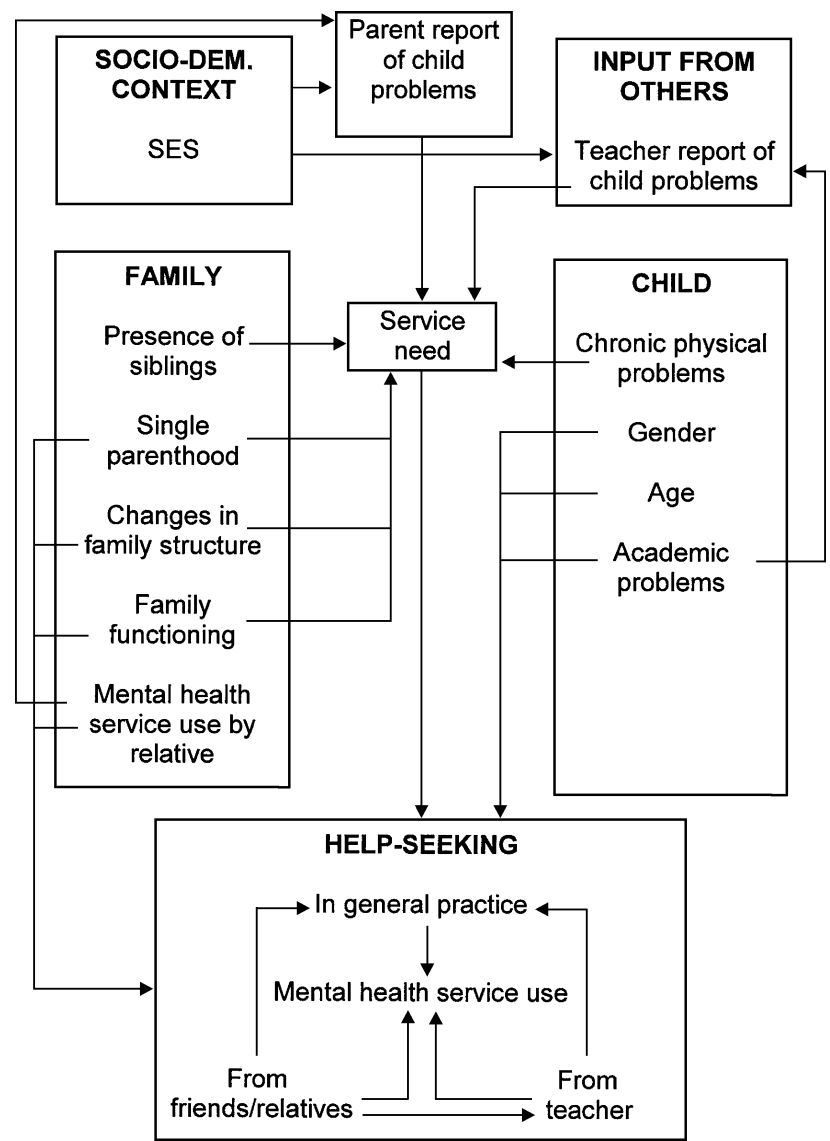

Fig. 1 Theoretical model of the help-seeking process and its determinants.

following variables are expected to be related to service need: child chronic physical problems, family functioning, changes in family structure, single parenthood, the presence of siblings, and the teacher's perception of child psychopathology.

Service need is hypothesized to precede help-seeking, which is investigated in both professional (general practice, mental health care) and informal service settings (teachers, friends/relatives). Because the threshold for seeking help from friends or relatives is considered to be lower than for any other kind of service, we assume that this kind of help-seeking precedes the use of other services. By including the GP as service provider, the gatekeeping role of Dutch GPs in the provision of mental health care is acknowledged and explicitly examined.

Help-seeking is assumed to be influenced by a child's gender, age, academic problems, family functioning, changes in family structure, single parenthood, and mental health service use by a relative (Briggs-Gowan et al., 2000; Feehan et al., 1994; Gunther et al., 2003; Jensen 
et al., 1990; John et al., 1995; Lavigne et al., 1998; Rickwood and Braithwaite, 1994; Verhulst and Van der Ende, 1997; Zahner and Daskalakis, 1997).

Some differentiations regarding the influence of determinants on the various components of the help-seeking process are included. First, based on previous results concerning the importance of the school in the detection of children with coexisting academic problems and the provision of care to these children (Verhulst and Van der Ende, 1997; Zahner and Daskalakis, 1997), academic problems are expected to affect service need through teachers' perceptions of child problems rather than through parents' reports of child symptoms and to be related to school service use only.

Because the acquaintance with a relative who has used mental health care has been suggested to sensitize parents to perceive problems in their child (Verhulst and Van der Ende, 1997), an association between this variable and parental report of child problems is expected. Furthermore, mental health care use by a relative is assumed to influence help-seeking from friends or relatives only (Rickwood and Braithwaite, 1994; Verhulst and Van der Ende, 1997).

Almost all Dutch inhabitants are registered within general practices, which are accessible to all and close to the community and provide generalist care. Because every inhabitant is, in principle, covered by private or public health insurance, no major financial constraints hamper the availability of care in the Dutch health care system. As was found for countries with comparable financial availability of health care (Gasquet et al., 1997, 1999; Sourander et al., 2001; Verhulst and Van der Ende, 1997), the socioeconomic indicators included in our model (education level, income, type of insurance) are expected not to affect service need or use directly. They are, however, hypothesized to affect the presence of child psychopathology.

Because of differences between health care systems, our theoretical model may not be directly applicable to nations in which health care depends more heavily on financial factors. In these countries, sociodemographic variables are likely to influence the help-seeking process (Briggs-Gowan et al., 2000; Pavuluri et al., 1996). Some systems also provide the opportunity of consulting mental health care without GP referral. Nevertheless, by testing a comprehensive help-seeking model as a whole instead of investigating its separate parts, we aim to provide a more generic method for studying help-seeking, which can be adapted to different health care systems.

\section{METHOD}

\section{Participants}

Our study involved a two-stage procedure. An overview of the study design and the numbers of respondents for the various stages of the study is presented in Figure 2. The base population for the study was derived from the Second Dutch National Survey of General Practice, which examined morbidity and treatment in a representative sample of 104 general practices with 195 GPs and 385,461 listed patients between April 2000 and January 2002. A random sample of the practice population was asked to participate in an extensive health interview survey. The total response rate was $64.5 \%$. Participants of this survey were comparable to the practice population with respect to gender, age, and place of residence (Westert et al., 2005).

As part of the interview, 1,319 parents completed the Child Behavior Checklist (CBCL; Achenbach, 1991a). Parents were also asked permission to send the Teacher's Report Form (TRF; Achenbach, 1991b) to the teacher who was the most familiar with the child's functioning. Responses were received from 974 teachers (180 respondents refused to give permission to contact the teacher, 64 teachers refused to cooperate, 96 teachers did not respond, and 5 children were too young to attend school). Children with available and missing TRF data were comparable with respect to age, gender, level of CBCL Total Problems scores, family constellation, and parental education level.

Parents of children scoring in the deviant range on CBCL or TRF Total Problems $(T \geq 60)$ were selected for participation in the second stage of the study. The response rate was $68.0 \%$. Children of secondstage respondents and nonrespondents were comparable with respect to

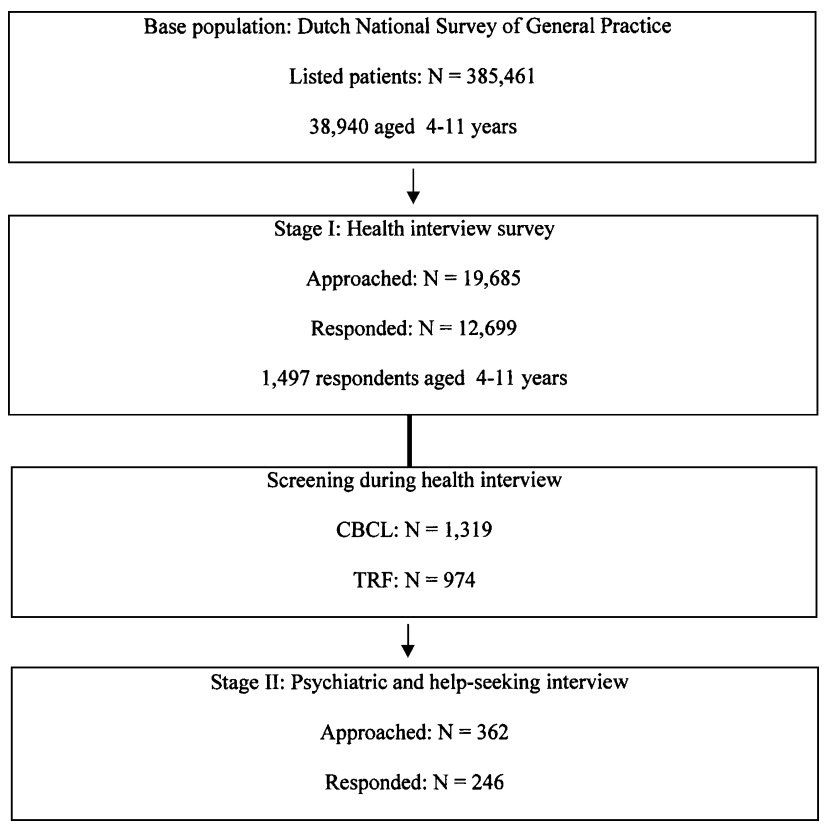

Fig. 2 Study design and numbers of respondents at various stages of the study. 
age, gender, and level of CBCL and TRF Total Problems scores. Nonparticipating parents were more likely to be living in single-parent families $(16 \%$ versus $8 \% ; p=.03)$ and to have lower education levels $(Z=-4.06$; $p=.00)$.

In the second stage (January 2001-July 2002), a standardized psychiatric interview (Diagnostic Interview Schedule for Children [DISC-IV]; Shaffer et al., 2000) was administered to the child's primary caregiver to obtain psychiatric diagnoses. Parents were also interviewed about their help-seeking actions.

\section{Measures}

CBCL. The CBCL (Achenbach, 1991a) was used to obtain standardized parents' reports of children's problem behaviors during the preceding 6 months. The CBCL has good reliability and discriminative validity in both American (Achenbach, 1991a) and Dutch (Verhulst et al., 1996) samples.

TRF. The TRF (Achenbach, 1991b) was used to obtain standardized teachers' reports of children's problems during the preceding 6 months. The good reliability and validity of the original TRF (Achenbach, 1991b) were confirmed for the Dutch version (Verhulst et al., 1997).

NIMH DISC-IV. This structured interview (DISC-IV; Shaffer et al., 2000) is designed to assess psychiatric disorders and associated functional impairment in children, using $D S M-I V$ criteria (American Psychiatric Association, 1994). Sections concerning anxiety disorders, mood disorders, and disruptive behavior disorders were used to obtain an indication of service need (see "Statistical Analyses").

Help-Seeking Interview. Help-seeking from professional and informal sources in the preceding 12 months and several child, family, and sociodemographic variables thought to be relevant for understanding the help-seeking process (Table 1) were assessed. Parental education level was scored on an 11-point scale, with 11 being the highest level. The parent with the highest education level was used to trichotomize the sample in low (scores 1-3), moderate (scores 4-8), and high (scores 9-11) education level. Family income was scored on a 5-point scale. Mean family income $(€ 2,168)$ was comparable to the income of the general Dutch population (http://statline. cbs.nl).

McMaster Family Assessment Device. During the second-stage interview, family functioning was measured by the Family Assessment Device (FAD) General Functioning scale (Epstein et al., 1983), which constitutes a reliable and valid global indicator of family functioning (Byles et al., 1988).

\section{Statistical Analyses}

Structural equation modeling (AMOS 4.0; Arbuckle and Wothke, 1999) was used to test the applicability of the theoretical model (Fig. 1) to our data. Central to this method of analysis is the notion that complex constructs (latent variables) can only be captured validly and reliably by using multiple indicators (observed variables). Our model contained six latent variables; all of the other variables were included as observed variables. CBCL Internalizing and Externalizing scores represented the latent variable Parent report of child problems, whereas TRF Internalizing and Externalizing scores represented the teacher's report of child problems. For the latent variable Family functioning, the 12 items of the FAD General Functioning scale were treated as observed variables. High scores reflect poor family functioning. The latent variable socioeconomic status (SES) was measured by variables indicating education level, family income, and type of insurance. Mental health service use
TABLE 1

Characteristics of Participants

\begin{tabular}{|c|c|c|}
\hline Participants & Characteristics & No. $^{a}$ \\
\hline \multicolumn{3}{|l|}{ Child } \\
\hline Gender & $\begin{array}{l}43.9 \% \text { girls (scored } 0) \\
56.1 \% \text { boys (scored } 1)\end{array}$ & 246 \\
\hline Age & 4-11; mean: 7.73; SD 2.32 & 246 \\
\hline Academic problems & $38.9 \%$ & 244 \\
\hline $\begin{array}{l}\text { Chronic physical } \\
\text { problems }\end{array}$ & $38.4 \%$ & 245 \\
\hline \multicolumn{3}{|l|}{ Family } \\
\hline Presence of siblings & $91.9 \%$ & 246 \\
\hline Single parenthood & $8.4 \%$ & 237 \\
\hline $\begin{array}{l}\text { Changes in } \\
\text { family structure }\end{array}$ & $10.2 \%$ & 245 \\
\hline $\begin{array}{l}\text { Mental health } \\
\text { service use by relative }\end{array}$ & $35.1 \%$ & 245 \\
\hline \multicolumn{3}{|l|}{ Sociodemographic context } \\
\hline Type of insurance & $53.5 \%$ public; $46.5 \%$ private & 243 \\
\hline Parental education level & $\begin{array}{l}13.1 \% \text { low; } 51.0 \% \\
\text { moderate; } 35.9 \% \text { high }\end{array}$ & 245 \\
\hline Family income & $\begin{array}{l}27.2 \%, \leq € 1,849 \\
19.1 \%, € 1,850-2,249 \\
26.0 \%, € 2,250-2,649 \\
26.8 \%, € 2,650-3,149 \\
0.9 \%, \geq € 3,150\end{array}$ & 235 \\
\hline
\end{tabular}

${ }^{a}$ Numbers of respondents for whom data were available.

was operationalized by two variables indicating different types of mental health service use.

The latent variable service need was operationalized by two DISC-IV variables, which indicated whether the child had any psychiatric diagnosis plus impairment on, respectively, internalizing (anxiety disorders and mood disorders) or externalizing (disruptive behavior disorders) diagnoses. Impairment was considered to be present when at least two of six diagnosis-specific DISC-IV impairment items indicating moderate or one item indicating severe personal, social, or academic difficulties were present. This operationalization of need corresponds to the definition of impairment as a global rather than diagnosis-specific concept (Bird et al., 2000).

Because $\chi^{2}$ tends to indicate a significant probability level as sample size increases (generally >200) (Schumacker and Lomax, 1996), other fit indexes were also inspected. A more detailed description of these indexes is available at www.jaacap.com via the Article Plus feature. Values of the root mean square error of approximation (RMSEA) $<0.05$ were considered to indicate a close model fit (Browne and Cudeck, 1993). Values of the non-normed fit index (NNFI; Bentler and Bonett, 1980) or Tucker-Lewis coefficient (TLI; Tucker and Lewis, 1973), close to 1 indicate a very good fit.

\section{RESULTS}

To gain insight into the severity of child problems in our sample, numbers of children with CBCL and TRF Internalizing and Externalizing scores in the deviant 
range are reported in Table 2. Note that continuous rather than dichotomous scores on these scales were used in the structural equation model. Rates of service need and service use are also reported in Table 2.

Figure 3 depicts, in a simplified version of Figure 1, the percentages of parents at various stages of the helpseeking process, thereby including our assumptions concerning the sequence of help-seeking stages. For the sake of clarity, internalizing and externalizing disorders were combined. A total of 180 parents indicated the presence of deviant internalizing and/or externalizing problems in their child. To do justice to the notion that only some parents move from one help-seeking stage to the next and others stay behind on a previous level, the percentages in Figure 3 are hierarchically ordered. This means that $60(33.3 \%)$ children, who were regarded as having deviant internalizing and/or externalizing problems, were also considered to be in need of help. Twenty percent of children in need of help used mental health services without consulting a GP, thereby passing by the gatekeeping role of the Dutch GP.

To increase our understanding of the GP's gatekeeping role, we investigated pathways to mental health services from a retrospective point of view (i.e., with mental health service use as starting point). Of the 38 parents using mental health services for their children, 16 (43.2\%) were referred by their GP, whereas $21(56.8 \%)$ ended up obtaining mental health care for their children through other pathways (information was not available

\section{TABLE 2}

Frequencies of Deviant Internalizing and Externalizing Problems, Service Need, and Service Use

\begin{tabular}{lcrr}
\hline & Rater & \multicolumn{1}{c}{$\%$} & \multicolumn{1}{c}{ No. $^{a}$} \\
\hline Internalizing problems & $\mathrm{P}$ & 58.1 & $143(246)$ \\
& $\mathrm{T}$ & 33.3 & $69(207)$ \\
Externalizing problems & $\mathrm{P}$ & 52.8 & $130(246)$ \\
& $\mathrm{T}$ & 45.4 & $94(207)$ \\
Internalizing + externalizing problems & $\mathrm{P}$ & 37.8 & $93(246)$ \\
& $\mathrm{T}$ & 17.9 & $37(207)$ \\
Internalizing service need & $\mathrm{P}$ & 15.0 & $37(246)$ \\
Externalizing service need & $\mathrm{P}$ & 20.3 & $50(246)$ \\
Internalizing + externalizing need & $\mathrm{P}$ & 6.9 & $17(246)$ \\
General practice & $\mathrm{P}$ & 13.1 & $32(245)$ \\
Mental health care & $\mathrm{P}$ & 15.4 & $38(246)$ \\
Teacher & $\mathrm{P}$ & 28.6 & $70(245)$ \\
Friends/relatives & $\mathrm{P}$ & 27.3 & $67(245)$ \\
\hline
\end{tabular}

Note: $\mathrm{P}=$ parent; $\mathrm{T}=$ teacher.

${ }^{a}$ In parentheses are the numbers of respondents for whom data were available.

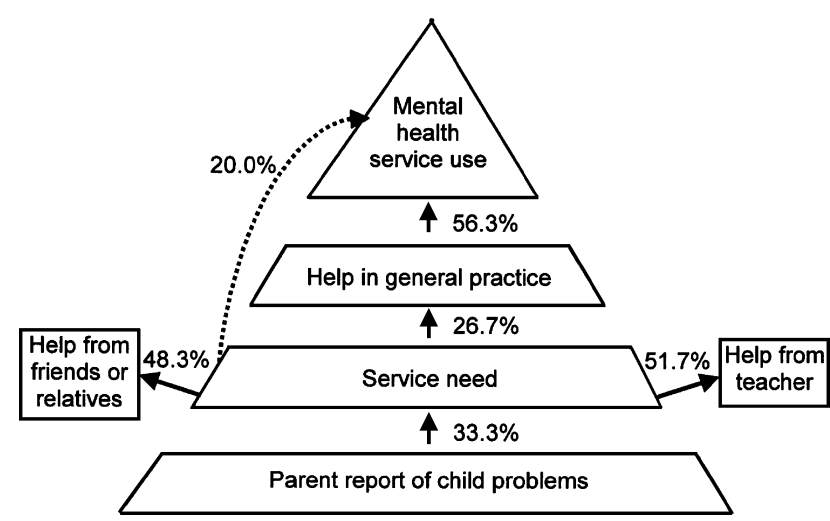

Fig. 3 Percentages of parents at various stages of the help-seeking process.

for one child). Whereas one third of these parents reached mental health care directly, two thirds got there with the help of other service providers, the majority of which came from school settings (e.g., school physicians, school psychologists, educational support services).

\section{Evaluation of the Structural Equation Model}

Our initial theoretical model as depicted in Figure 1 did not yield an adequate fit (model $\mathrm{A} ; \chi^{2}=921.29 ; d f=$ 496; $p<.001$; RMSEA $=0.059$; NNFI/TLI $=0.957$ ). To increase model fit, some modifications were made. Values of fit indexes for subsequent models in the process of improving fit are available at www.jaacap.com via the Article Plus feature. First, because of the considerable percentage of parents consulting mental health professionals directly rather than via the GP as gatekeeper (Fig. 3), the first modification included adding a direct link between service need and mental health service use (model B). Consequently, nonsignificant paths were deleted from the original model one by one (model C). Finally, modification indexes were inspected and only those with theoretical relevance and that resulted in a considerable improvement of model fit were imputed. Because these indexes cannot be computed with incomplete data, they were computed for the part of the sample with complete data $(N=183)$. These indexes suggested adding a path from child gender to teacher report of child problems, and adding correlations between (1) child age and academic problems, (2) single parenthood and changes in family structure, (3) single parenthood and SES, and (4) mental health service use by relative and family functioning. This significantly increased model fit (model $\mathrm{D} ; \chi^{2}=819.56 ; d f=516$; $p<.001 ;$ RMSEA $=0.049 ; \mathrm{NNFI} / \mathrm{TLI}=0.970)$. 
Although a significant $\chi^{2}$ normally indicates an inappropriate model fit, we still perceive the model as appropriate, as indicated by other goodness-of-fit measures.

The standardized regression weights and correlations for the structural part of this final model are depicted in Figure 4. To decrease the complexity of this figure, parameters associated with the measurement model are not included. Within the measurement model, factor loadings for each observed variable were positive and significant at $p<.001$. Standardized loadings ranged from 0.35 to 0.85 , with a median of 0.59 (see Article Plus for more details).

\section{DISCUSSION}

This study was aimed at investigating in one comprehensive model the process of help-seeking for child

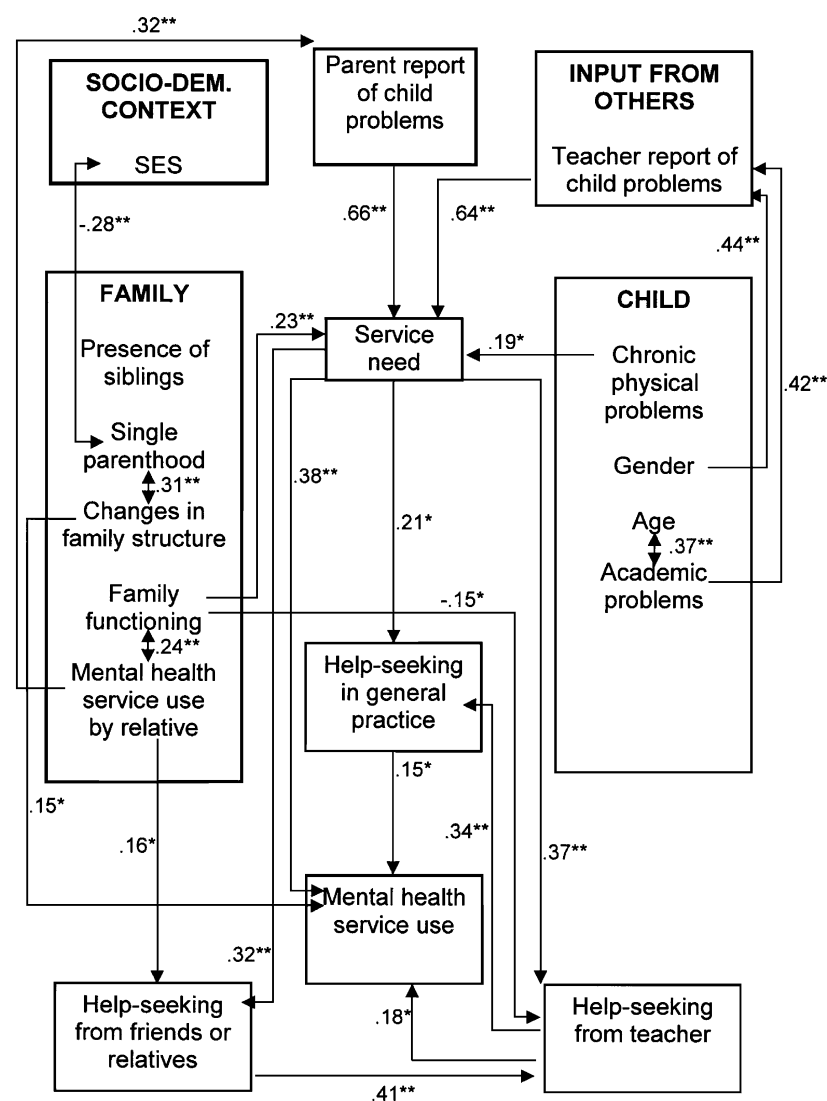

Fig. 4 Final structural model. Presented are correlations (double-headed arrows) and standardized regression weights (single-headed arrows). Parent report of child problems, teacher report of child problems, family functioning, socioeconomic status (SES), and mental health service use were included as latent variables. Parameters associated with the measurement model were not included to decrease the complexity of the figure (see Article Plus). ${ }^{*} p<.05 ;{ }^{* *} p<.01$. psychopathology in both professional and informal service settings. By means of structural equation modeling, characteristics of the child, family, and context were investigated as determinants of various stages in the helpseeking process.

In general, structural equation modeling proved to be a fruitful method for concurrently testing associations between various stages in the help-seeking process and their hypothesized determinants. We believe that the merits of this method are not restricted to countries with comparable health care systems, but consider it also useful as a more generic approach for clarifying the helpseeking processes in other countries. Although it is likely to produce different results depending on the health care systems in which it is used, a general use of this approach will increase comparability of results.

Based on their gatekeeping role in the Dutch health care system, GPs were expected to play a central role in our model. Contrary to expectation, however, the percentages of parents at subsequent stages of the helpseeking process (Fig. 3), as well as the regression weights in our help-seeking model (Fig. 4), indicated that only a minority of children in need of help actually received help from their GP. The GP's role as gatekeeper of mental health care was also limited. These findings may be explained by GPs' limitations in adequately recognizing psychopathology in young children (Sayal and Taylor, 2004; Zwaanswijk et al., 2005).

As in many countries, demand for child mental health care in the Netherlands exceeds supply. Although the limited availability of mental health services can partly explain the limited number of children with disorders receiving mental health care in general, it cannot explain the limited gatekeeping role of the Dutch GP because parents still managed to find their way into child mental health care, either directly or with the help of other service providers.

Another possible explanation for parents seeking help from mental health services without GP referral could be the fact that these help-seeking actions involved follow-up consultations for persisting child problems. In that case, GP referral may have taken place more than 1 year ago and have fallen outside the time range assessed in our study. Of the 21 children who entered mental health care without GP referral, only 4 (19.0\%) had used the same kind of mental health care in the period before the year of assessment and were therefore likely to be in long-term contact with these 
services. For the remaining $81 \%$, this possibility was ruled out.

A considerable number of children entered mental health care with the help of school-based service providers instead of the GP. During primary education, most Dutch children are routinely screened for physical and psychosocial problems by school physicians. This screening apparently plays an important role in the detection and referral of child psychopathology. In addition to this, the teacher was found to be an important source of help. These findings are in concordance with previous studies, in which the education sector was indicated as the most commonly used source of help for child psychopathology (Burns et al., 1995; Farmer et al., 2003; Ford et al., 2003).

Several variables in child, family, and context were investigated as determinants of the help-seeking process. Remarkably, the impact of child characteristics appeared to be marginal. Some of these variables (child gender and coexisting academic problems) did exert their influence on the help-seeking process only indirectly through their impact on the teacher's perception of child problems, whereas child age influenced neither service need nor help-seeking. The only child characteristic directly influencing the help-seeking process was the presence of coexisting chronic physical problems, which was associated with an increased service need (see, e.g., Verhulst and Van der Ende, 1997).

Family characteristics had a stronger impact on the help-seeking process, although the previously found influence of family structure and size (i.e., single parenthood and the presence of siblings; Briggs-Gowan et al., 2000; Jensen et al., 1990; Verhulst and Van der Ende, 1997) could not be detected in our data. Changes in family structure were shown only to influence mental health service use, without affecting service need or help-seeking in other settings.

Remarkable is the differential effect of family functioning on service need and help-seeking. Although service need is significantly present in poorly functioning families, parents in these families seem to experience barriers in actually seeking teachers' help. In contrast with previous findings (Lavigne et al., 1998; Verhulst and Van der Ende, 1997), family functioning was not directly related to other types of help-seeking.

As expected (Verhulst and Van der Ende, 1997), the presence of a relative who had used mental health services increased the likelihood of parents perceiving problems in their child without directly increasing service need. It also increased the chance of parents using support of family and friends (see, e.g., Rickwood and Braithwaite, 1994). The presence of a relative who has consulted mental health services may indicate a certain willingness to discuss mental health matters in the family system, which may facilitate help-seeking for child psychopathology within this system.

An important context factor influencing the helpseeking process was the teacher's perception of child problems. This variable was almost as strongly related to service need as the parents' own report of child problems, which is remarkable considering the limited agreement between parent and teacher reports of child problems (Achenbach et al., 1987). This finding again indicates the influential role of teachers in the help-seeking process.

Sociodemographic context variables (parental education level, family income, type of insurance) were confirmed not to influence the help-seeking process directly. This finding can probably be ascribed to the Dutch health care system in which major financial constraints to the availability of care are lacking.

\section{Limitations}

Because of differences between countries' health care systems, caution should be exercised in generalizing these results to nations with systems that are not like the Dutch (i.e., with financial constraints for receiving care and without the GP as gatekeeper). We therefore advocate using our method with help-seeking models adapted to other health care systems. We believe our results concerning the importance of schools and schoolbased service providers in the help-seeking process for child psychopathology to be of more general value.

Generalizability may be hampered by the relatively low response rates at the two stages of the study. In addition, parents from single-parent families and lesseducated parents were less likely to participate in the study. Because these characteristics have generally been shown to be associated with elevated levels of child problems, this study may underestimate the presence of child psychopathology. The finding that CBCL and TRF Total Problems scores did not differ between participants and nonparticipants argues against this possibility, however. The fact that no confirmation was found for the previously reported associations between 
SES and child psychopathology and among single parenthood, service need, and service use may be the result of the underrepresentation of less-educated and singleparent families in our sample.

Although the assumptions in our model were based on theory and associations established in previous research, and our final model adequately fit the data, we acknowledge the relatively data-driven nature of model adjustment (e.g., removing nonsignificant associations and adding some associations suggested by modification indexes). Therefore, future studies, preferably longitudinal ones, are needed to confirm our findings and establish causal directionality of the associations found. Longitudinal studies, similar to that of Farmer et al. (2003), could also shed more light on the sequence of help-seeking stages.

The results of this study may be biased because of the reliance on parent reports of service need and use. Our indicator of service need is more objective than used in previous studies, in which parents are directly asked whether their child is in need of help. Whereas our measure corresponds better with formal diagnostic criteria, a more direct reflection of parents' need for services may give a better view of parents' own reality. The finding that parents' report of the presence of child problems exerts its influence on the four help-seeking variables only indirectly, through service need, suggests that our measure of service need discriminates between parents who do experience problems in their child but are able to manage these problems without help and parents for whom the impact of child problems is strong enough to require outside help.

With respect to the parent reports of service use, we believe parents to be the best informants on service use for this young age group. Previous evidence suggests that parent reports are reasonably accurate compared to administrative records (Fendrich et al., 1999). Because parents may have difficulties discriminating among multiple service settings (Bean et al., 2000), however, rates of service use may be biased. Including additional sources of data may strengthen our findings.

Help-seeking for child psychopathology is a complex process, and although we tried to capture some of its key aspects, others deserve attention in future research. Although the present study was primarily focused on stages, actors, and determinants involved in the process of help-seeking, parents' reasons for not seeking help were not directly assessed. Progress on the pathway to care can, for instance, also be hindered by characteristics of the health care system or by parents' perceptions of services or service providers (see, e.g., Pavuluri et al., 1996).

\section{Clinical Implications}

Based on this study, several groups at which interventions to increase child mental health service use may be directed were identified. First, educating parents about the nature and prevalence of child psychopathology may raise their awareness of the possible presence of such problems. Parents who do not use services despite their service needs may benefit from information on the availability and accessibility of care, and parents from poorly functioning families may need a more actively outreaching approach to overcome barriers on the help-seeking pathway.

Another way to increase child mental health service use may be the improvement of GPs' skills in detecting child psychopathology. Direct contact between GPs and mental health professionals may have a consultative function, may facilitate referral, and may accelerate access to services.

Improving the detection and referral of child problems is, however, only useful if services are sufficiently available to meet the demands of children. Schools are therefore encouraged to liaise with external professionals who may provide less-intensive forms of care within schools. Direct contact between schools and mental health care professionals may also ameliorate problem detection within schools and shorten the pathway to specialist care.

Clinicians should try to assess whether parents' resources are sufficient to cope with the demands of having a disordered child. For some parents, offering assistance for some of the additional stressors associated with service need and use may be enough to avoid use of more specialized services.

Disclosure: The authors have no financial relationships to disclose.

\section{REFERENCES}

Achenbach TM (1991a), Manual for the Child Behavior Checklist/4-18 and 1991 Profiles. Burlington: University of Vermont Department of Psychiatry 
Achenbach TM (1991b), Manual for the Teacher's Report Form and 1991 Profiles. Burlington: University of Vermont Department of Psychiatry

Achenbach TM, McConaughy SH, Howell CT (1987), Child/adolescent behavioral and emotional problems: implications of cross-informant correlations for situational specificity. Psychol Bull 101:213-232

American Psychiatric Association (1994), Diagnostic and Statistical Manual of Mental Disorders, 4th edition (DSM-IV). Washington, DC: American Psychiatric Association

Andersen RM (1995), Revisiting the behavioral model and access to medical care: does it matter? J Health Soc Behav 36:1-10

Arbuckle JL, Wothke W (1999), Amos 4.0 User's Guide. Chicago: SmallWaters

Bean DL, Leibowitz A, Rotheram-Borus MJ et al. (2000), False-negative reporting and mental health services utilization: parents' reports about child and adolescent services. Ment Health Serv Res 2:239-249

Bentler PM, Bonett DG (1980), Significance tests and goodness of fit in the analysis of covariance structures. Psychol Bull 88:588-606

Bird HR, Davies M, Fisher P et al. (2000), How specific is specific impairment? J Am Acad Child Adolesc Psychiatry 39:1182-1189

Brewin C, Wing J, Mangen S, Brugha T, MacCarthy B (1987), Principles and practice of measuring needs in the long-term mentally ill: the MRC Needs for Care Assessment. Psychol Med 17:971-981

Briggs-Gowan MJ, Horwitz S, Schwab-Stone M, Leventhal JM, Leaf PJ (2000), Mental health in pediatric settings: distribution of disorders and factors related to service use. J Am Acad Child Adolesc Psychiatry 39:841-849

Browne MW, Cudeck R (1993), Alternative ways of assessing model fit. In: Testing Structural Equation Models, Bollen KA, Long JS, eds.Newbury Park, CA: Sage Publications, pp 136-162

Burns BJ, Costello EJ, Angold A et al. (1995), Children's mental health service use across service sectors. Health Aff 14:147-159

Byles J, Byrne C, Boyle MH, Offord DR (1988), Ontario Child Health Study: Reliability and validity of the General Functioning subscale of the McMaster Family Assessment Device. Fam Proc 27:97-104

Costello EJ, Pescosolido BA, Angold A, Burns BJ (1998), A family networkbased model of access to child mental health services. Res Comm Ment Health 9:165-190

Epstein NB, Baldwin LM, Bishop DS (1983), The McMaster Family Assessment Device. J Marital Fam Ther 9:171-180

Farmer EZ, Burns BJ, Phillips SD, Angold A, Costello EJ (2003), Pathways into and through mental health services for children and adolescents. Psychiatr Serv 54:60-66

Feehan M, Stanton W, McGee R, Silva P (1994), A longitudinal study of birth order, help seeking and psychopathology. Br J Clin Psychol 33:143-150

Fendrich M, Johnson T, Wislar J, Nageotte C (1999), Accuracy of parental mental health service reporting: results from a reverse record-check study. J Am Acad Child Adolesc Psychiatry 38:147-155

Fischer EH, Weiner D, Abramowitz S (1983), Seeking professional help for psychological problems. In: New Directions in Helping, Vol. 3: Applied Perspectives in Help-Seeking and Receiving, Nadler A, Fisher JD, DePaulo BM, eds. New York: Academic Press, pp 163-212

Flisher AJ, Kramer RA, Grosser RC et al. (1997), Correlates of unmet need for mental health services by children and adolescents. Psychol Med 27:1145-1154

Ford T, Goodman R, Meltzer H (2003), Service use over 18 months among a nationally representative sample of British children with psychiatric disorder. Clin Child Psychol Psychiatry 8:37-51

Gasquet I, Chavance M, Ledoux S, Choquet M (1997), Psychosocial factors associated with help-seeking behavior among depressive adolescents. Eur Child Adolesc Psychiatry 6:151-159

Gasquet I, Ledoux S, Chavance M, Choquet M (1999), Consultation of mental health professionals by French adolescents with probable psychiatric problems. Acta Psychiatr Scand 99:126-134

Goldberg D, Huxley P (1980), Mental Illness in the Community: The Pathway to Psychiatric Care. New York: Tavistock
Goldberg D, Huxley P (1992), Common Mental Disorders: A Bio-social Model. London: Routledge

Gunther N, Slavenburg B, Feron F, Van Os J (2003), Childhood social and early developmental factors associated with mental health service use. Soc Psychiatry Psychiatr Epidemiol 38:101-108

Jensen PS, Bloedau L, Davis H (1990), Children at risk: II. Risk factors and clinic utilization. J Am Acad Child Adolesc Psychiatry 29:804-812

John LH, Offord DR, Boyle MH, Racine YA (1995), Factors predicting use of mental health and social services by children $6-16$ years old: findings from the Ontario Child Health Study. Am J Orthopsychiatry 65:76-86

Lavigne JV, Arend R, Rosenbaum D et al. (1998), Mental health service use among young children receiving pediatric primary care. J Am Acad Child Adolesc Psychiatry 37:1175-1183

Leaf PJ, Alegria M, Cohen P, et al. (1996), Mental health service use in the community and schools: results from the four-community MECA study. J Am Acad Child Adolesc Psychiatry 35:889-897

Logan DE, King CA (2001), Parental facilitation of adolescent mental health service utilization: a conceptual and empirical review. Clin Psychol Sci Pract 8:319-333

Pavuluri MN, Luk S, McGee R (1996), Help-seeking for behavior problems by parents of preschool children: a community study. J Am Acad Child Adolesc Psychiatry 35:215-222

Rickwood DJ, Braithwaite VA (1994), Social-psychological factors affecting help-seeking for emotional problems. Soc Sci Med 39:563-572

Sayal K, Taylor E (2004), Detection of child mental health disorders by general practitioners. Br J Gen Pract 54:348-352

Schumacker RE, Lomax RG (1996), A Beginner's Guide to Structural Equation Modeling. Mahwah, NJ: Lawarence J. Erlbaum Associates

Shaffer D, Fisher P, Christopher PL, Dulcan MK, Schwab-Stone ME (2000), NIMH Diagnostic Interview Schedule for Children Version IV (NIMH DISC-IV): description, differences from previous versions, and reliability of some common diagnoses. J Am Acad Child Adolesc Psychiatry 39:28-38

Sourander A, Helstela L, Ristkari T, Ikaheimo K, Helenius H, Piha J (2001), Child and adolescent mental health service use in Finland. Soc Psychiatry Psychiatr Epidemiol 36:294-298

Tucker LR, Lewis C (1973), A reliability coefficient for maximum likelihood factor analysis. Psychometrika 38:1-10

Verhulst FC, Koot JM (1992), Child Psychiatric Epidemiology: Concepts, Methods and Findings. Beverly Hills, CA: Sage Publications

Verhulst FC, Van der Ende J (1997), Factors associated with child mental health service use in the community. J Am Acad Child Adolesc Psychiatry 36:901-909

Verhulst FC, Van der Ende J, Koot HM (1996), Handleiding voor de CBCL/ 4-18 [Manual for the CBCL/4-18]. Rotterdam: Afdeling Kinder- en Jeugdpsychiatrie, Sophia Kinderziekenhuis/Academisch Ziekenhuis Rotterdam/Erasmus Universiteit Rotterdam

Verhulst FC, Van der Ende J, Koot HM (1997), Handleiding voor de Teacher's Report Form (TRF) [Manual for the Teacher's Report Form (TRF)]. Rotterdam: Afdeling Kinder- en Jeugdpsychiatrie, Sophia Kinderziekenhuis/Academisch Ziekenhuis Rotterdam/Erasmus Universiteit Rotterdam

Westert GP, Schellevis FG, De Bakker DH, Groenewegen PP, Bensing JM, Van der Zee J (2005), Monitoring health inequalities through general practice: the Second Dutch National Survey of General Practice. Eur J Public Health 15:59-65

Zahner GP, Daskalakis C (1997), Factors associated with mental health, general health, and school-based service use for child psychopathology. Am J Public Health 87:1440-1448

Zwaanswijk M, Van der Ende J, Verhaak PM, Bensing JM, Verhulst FC (2003), Factors associated with adolescent mental health service need and utilization. J Am Acad Child Adolesc Psychiatry 42:692-700

Zwaanswijk M, Verhaak PM, Van der Ende J, Bensing JM, Verhulst FC (2005), Consultation for and identification of child and adolescent psychological problems in Dutch general practice. Fam Pract 22:498-506 